\title{
Covid-19: Rest and PPE reassurance are needed before NHS services can restart, MPs hear
}

\author{
Jacqui Wise \\ London
}

NHS staff are exhausted from the covid-19 pandemic and will need time to rest and recover before the health service can get back up to capacity, MPs have been told.

At a Health and Social Care Select Committee evidence session on 14 May the King's Fund, the Nuffield Trust, and the Health Foundation warned that it would take many more months before core health and care services were able to fully restart.

The charities said that government and health leaders should not underestimate the high levels of stress and exhaustion in the NHS and social care and that workers would need reassurance that adequate protection against the virus was in place before restarting services. The public might also be reluctant to use NHS and social care services for fear of infection and would also need reassurance, they said.

Latest NHS England figures show that covid-19 has had a significant impact on planned operations and appointments, as a lower percentage of patients have been treated within 18 weeks than at any time since June $2008 .{ }^{1}$

Referrals for treatment have fallen to the lowest level ever recorded. The total number of referrals in March 2020 was 1.2 million, down nearly 400000 on the previous month. The number of patients waiting more than 52 weeks to start planned treatment had nearly doubled from 1613 to 3097.

\section{Limited capacity}

Jennifer Dixon, chief executive officer at the Health Foundation, told the committee that capacity within hospitals would be severely limited because of the need for social distancing, separating out covid and non-covid patients, and more time for deep cleaning of equipment and facilities.

Most hospitals will not physically have the space for social distancing once demand in emergency departments reverts to normal levels, said Nigel Edwards, chief executive officer at the Nuffield Trust. He called for "imaginative thinking"-for example, by copying countries such as Denmark, where patients are not allowed to simply turn up at emergency departments. Instead he suggested that they would first have to contact the NHS 111 service or their GP.

Chris Hopson, chief executive officer at NHS Providers, told the committee that NHS staff had worked incredibly hard in the past few months, with leave cancelled, and were very tired as a result. He said that, before the health service gets back up to capacity, NHS staff would "need time to rest and recover."

Hopson highlighted a need for routine weekly covid-19 testing of staff. He also said that, because of a shortage of gowns, trusts had been forced to use sterile ones usually reserved for surgical operations. He was concerned that this meant no "reliable and consistent flow" of surgical gowns to fully restart surgical operations.

On the supply of personal protective equipment, he said that the situation was not as hand to mouth as it was three to four weeks ago but was still a "work in progress."

NHS England. Consultant-led referral to treatment waiting times data 2019-20. https:// www.england.nhs. uk/statistics/statistical-work-areas/rtt-waiting-times/rtt-data-2019-20/.

Published by the BMJ Publishing Group Limited. For permission to use (where not already granted under a licence) please go to http://group.bmj.com/group/rights-licensing/ permissions 